\title{
Prevalence and antibiogram of Shigella and Salmonella spp. from under five children with acute diarrhea in Bahir Dar Town
}

\author{
Maritu Admassu $^{1}$, Gebremariam Yemane ${ }^{1}$, Mulugeta Kibret ${ }^{1 *}$, Bayeh Abera $^{2}$, Endalkachew Nibret ${ }^{1}$ and Melaku \\ Adal $^{1}$
}

Department of Biology, Science College*, Bahir Dar University, P. O. Box 79, Bahir Dar, Ethiopia

${ }^{2}$ Department of Microbiology, Parasitology and Immunology, College of Medicine and Health Sciences

Bahir Dar University, P. O. Box 79, Bahir Dar, Ethiopia

\begin{abstract}
Diarrheal diseases remain the major cause of morbidity and mortality in children under five years of age. Salmonella and Shigella species are among the leading causes of diarrhea in children. The aim of this study was to determine the prevalence and antimicrobial profiles of Salmonella and Shigella spp. in children less than five years of age with acute diarrhea. A cross sectional study was conducted among 422 children with diarrhea from December 2011 to February 2012. A structured questionnaire was used to collect socio-demographic and clinical data. Identification of Salmonel$l a$ and Shigella species and antimicrobial susceptibility tests was done following standard microbiology procedures. The overall prevalence of Salmonella and Shigella was 7.8\% and $9.5 \%$, respectively. The isolation rates of S. flexineri, S.dysenteri and S. boydii were 18 (45\%), 12 (30\%) and 10 (25\%), respectively. The prevalence of Salmonella and Shigella were not statistically significant along age groups and gender of the children. Most of Salmonella and Shigel$l a$ were resistant to ampicillin (> 88.7\%) and cotrimoxazole (50\%).In contrast, 83.3-89.9\% of isolates showed susceptible to norfloxacin, ciprofloxacin and gentamicin. More than $90 \%$ of the Salmonella and $80 \%$ Shigella spp. were multiple drug resistant. High prevalence of Shigella and Salmonella linked with high levels of antimicrobial resistance is a major public health concern in the study area. Continuous surveillance of antimicrobial susceptibility should be done. Ciprofloxacin, norfloxacin and gentamicin appeared to be drugs of choice for empirical treatment of these infections.
\end{abstract}

Keywords: Shigella, Salmonella antimicrobial susceptibility, diarrhea, Ethiopia

DOI: http://dx.doi.org/10.4314/ejst.v8i1.3

\section{INTRODUCTION}

Diarrhea is the leading causes of death among children under the age offive, particularly in the developing world (WHO, 2013), Elias, 2008). Diarrhea kills more young children than AIDS, malaria and measles combined (UNICEF/WHO, 2009). In developing countries, acute bacterial diarrhea is frequently disabling, recurrent, and significantly contributes to malnutrition and death (Rodríguez et al., 2011). In Ethiopia, diarrhea accounts to about $20 \%$ of death in $0-5$ years age (FMoH, 2011). Diarrheal disease affects rich and poor, old and young, and those in developed and developing countries alike, yet a strong relationship exists between poverty, an unhygienic environment, and the number and severity of diarrheal episodes especially for under five children (Keusch et al., 2006) . Globally, it is estimated that shigellosis causes about 1,1 million deaths per year, two-thirds of the patients being children under 5 years of age (Ranjbar et al., 2008). Despite scientific advances over the past century, the epidemiological characteristics, virulence and ability to develop drug resistance has led to renewed and increased incidence of Shigella (Ranjibar et al., 2008). Salmonellosis represents a major communicable worldwide disease problem (Laurent et al., 2005). Salmonellae may be present in all kinds of food grown in faecally polluted

\footnotetext{
*Corresponding author:mulugetanig@,gmail.com

(C) This is an Open Access article distributed under the terms of the Creative Commons Attribution License (http://creativecommons.org/licenses/CC BY4.0)
} 
environments, and are commonly isolated from poultry and livestock and foods prepared from them. The threat to human health posed by antibiotic resistance is of growing concern.

Studies from developed and developing countries showed that multidrug resistant Salmonella and Shigella was increasing from time to time (Kariuki et al., 2006; Gizachew Yismaw et al., 2006). Pathogen occurrence and susceptibility profiles show substantial geographic variations as well as significant differences in various populations and environments (Leegaard et al., 2000; Nagal et al., 2006). However, few studies have been conducted on the prevalence of these pathogens in Ethiopia (Moges Tiruneh, 2009; Getachew Debas et al., 2011). Thus, updated data on Salmonella and Shigella at the local level is required for appropriate recommendations for optimal empirical therapy. Therefore, this study was conducted to determine the prevalence and antibiogram of Salmonella and Shigella spp. in under five children in Bahir Dar Town, Ethiopia.

\section{METHODS}

\section{Study area}

The study was conducted in Bahir-Dar which is the capital of Amhara National Regional State, located northwestern Ethiopia approximately $578 \mathrm{~km}$ from Addis Ababa. The town has latitude and longitude of $11^{\circ} 36^{\prime} \mathrm{N} 37^{\circ} 23^{\prime} \mathrm{E}$ and an elevation of 1840 meters above sea level. The town has a total population of 256,999 (CSA, 2011). This study was specifically conducted at Arsema and Universal Pediatric clinics.

\section{Study design and period}

A cross-sectional study was conducted in two pediatric clinics in Bahir Dar between December 2011 and February 2012. Children under five years of age attending pediatric clinics were considered in the study.
Diarrhea was defined as the passage of 3 or more liquid stools in a 24 hour period.

\section{Study population, sample size and sampling}

All children under five years of age who visited Arsema and Universal Pediatric clinics with acute diarrhea and whose caretakers were willing to participate in the study were included in the study. A minimum sample size of 384 was calculated using single population proportion formula, assuming 95\% confidence interval, $50 \%$ prevalence and margical error of $5 \%$ (Daniel, 1999). A 10\% contingency (38) was added and a sample size of 422 was obtained. The study participants were selected using systematic random sampling method. Considering average monthly diarrhea cases of 230 in each clinic, the estimated total number of diarrheal cases, $\mathrm{N}$, for the study period was, $4 * 460$ $=1840$. To obtain a sample size of 422 , the selection interval, $\mathrm{K}$, was calculated using the following formula, $K=N / n=1840 / 422$. Hence, it was decided to include every fourth case in the sample.

\section{Inclusion criteria}

Children aged less than five years with acute diarrhea who visited Arsema and Universal pediatric clinics whose caretakers were willing to participate in the study were included.

\section{Exclusion criteria}

Children aged greater or equal to 5 years and children who were on antibiotic therapy for two weeks. , Children having diarrhea of more than 14 days and those whose caretakers did not agree to give samples were excluded from this study.

\section{Sample Collection}

A total of 422 stool samples were collected with sterile plastic containers by experienced laboratory technicians. The specimens were transported in ice-box to the Microbiology Laboratory of Bahir Dar University and analyzed for detection of Salmonella and Shigella 
spp. A pre-tested structured questionnaire was used to collect socio-demographic characteristics and clinical data of the children.

\section{Culture and identification}

Stool samples were enriched in Selenit F broth for 8 hours prior to inoculating into MacConkey agar and Xylose-lysine deoxycholate (XLD) agar (Oxoid, England). The plates were incubated under aerobic atmosphere at $37^{\circ} \mathrm{C}$ and examined after 24 hours. Typical colorless colonies on MacConkey agar and pink to red colonies on XLD agar were picked and further identified through a series of biochemical tests as per standard method (Collins and Lyne, 2004; Cheesbrough, 2006). Serological identification of Shigella species was performed by slide agglutination test (Cheesbrough, 2006). The antisera used for Shigella serotypes identification were: $S$. boydii polyvalent 1(1-6), $S$ boydii polyvalent 2(7-11), S. boydii polyvalent 3(12-15), S. dysenteriae polyvalent (1-10), S. flexineri polyvalent (1-6, X \& Y), and S. sonnei (phase 1 and 2) (Oxoid, England).

\section{Antimicrobial susceptibility testing}

In Vitro antimicrobial susceptibility testing was performed for 33 Salmonella and 40 Shigella isolates on Mueller-Hinton Agar (Oxoid, England) using disk diffusion technique (Bauer et al., 1966). The antimicrobials tested were: ampicillin $(10 \mu \mathrm{g})$, amoxicillin/clavulanic acid $(20 / 10 \mu \mathrm{g})$, tetracycline $(30 \mu \mathrm{g}), \quad$ gentamicin $\quad(10 \mu \mathrm{g}), \quad$ chloramphenicol $(30 \mu \mathrm{g})$, norfloxacin $(10 \mu \mathrm{g})$, ciprofloxacin $(5 \mu \mathrm{g})$, Trimethoprim-sulfamethoxazole $(1.25 / 23.75 \mu \mathrm{g})$ and ceftizoxime $(30 \mu \mathrm{g})$ (Oxoid, UK). Morphologically identical 4-6 bacterial colonies from overnight culture were suspended in $5 \mathrm{ml}$ nutrient broth and incubated for 4 hours at $37^{\circ} \mathrm{C}$. Turbidity of the broth culture was equilibrated to match 0.5 McFarland standards. The surface of Mueller Hinton agar plate was evenly inoculated with the culture using a sterile cotton swab. The antibiotic discs were applied on the surface of the inoculated agar. After 18-24 hours of incubation, the diameter of growth inhibition around the discs were measured and interpreted as sensitive, intermediate or resistant according to Clinical and Laboratory Standards Institute (CLSI, 2011). Reference strain of E. coli ATCC 25922 was used as quality control for antimicrobial susceptibility tests.

\section{Data analysis}

Data were analyzed using the Statistical Package for Social Sciences version 20 software (IBM Corp. Released 2011. IBM SPSS Statistics for Windows, Armonk, NY: IBM Corp). Association between socio-demographic characteristics of the study participants, some clinical data and prevalence of Salmonella and Shigella analyzed using chi-square test, and a p-value of less than 0.05 was considered statistically significant.

\section{Ethical consideration}

The study was ethically approved by the Institutional Ethics Review Board of Bahir Dar University. Written consent was obtained from parents/guardians of the child before enrolment into the study.

\section{RESULTS AND DISCUSSION}

A total of 422 children (239 males and 183 females) aged 0-59 months with acute diarrhea were enrolled in the study. Of the 76 children below six months, 32 were exclusively breastfed. Two hundred and eighty one $(66.6 \%)$ children exhibited non bloody diarrhea followed by watery diarrhea in 134 (31.8\%) while 7 (1.6\%) had bloody diarrhea (Table 1).

Both Salmonella (2.6\%) and Shigella (2.9\%) were highly prevalent in children of age category 6-11 months. However, the differences were not statistically significant along age groups and gender of the children (Table 1). Non-bloody mucoid was the most 
able1. Socio-demographic characteristics and clinical data of the study subjects and prevalence of Shigella, spp. and Salmonella at Bahir Dar Health, Ethiopia, $2012(\mathrm{n}=244)$

\begin{tabular}{|c|c|c|c|c|c|c|}
\hline Variables & & onella & & Shigella & & \\
\hline & $\begin{array}{l}\text { Positive } \\
\text { No }(\%)\end{array}$ & $\begin{array}{l}\text { Negative } \\
\text { No }(\%)\end{array}$ & $\mathrm{P}$ value & $\begin{array}{l}\text { Positive } \\
\text { No }(\%)\end{array}$ & $\begin{array}{l}\text { Negative } \\
\text { No }(\%)\end{array}$ & P-value \\
\hline $\begin{array}{c}\text { Age (months ) } \\
0-5 \\
6-11 \\
12-23 \\
24-35 \\
36-47 \\
48-59\end{array}$ & $\begin{array}{l}8(1.9) \\
12(2.9) \\
8(1.9) \\
3(0.7) \\
0(0.0) \\
2(0.5)\end{array}$ & $\begin{array}{l}53(12.6) \\
106(25.1) \\
133(31.5) \\
52(12.3) \\
28(6.6) \\
17(4.0)\end{array}$ & 0.2 & $\begin{array}{l}7(1.7) \\
11(2.6) \\
5(1.2) \\
2(0.5) \\
4(0.9) \\
11(2.6)\end{array}$ & $\begin{array}{l}54(12.8) \\
107(25.4) \\
103(24.4) \\
31(7.3) \\
30(7.1) \\
57(13.5)\end{array}$ & 0.17 \\
\hline $\begin{array}{l}\text { Male } \\
\text { Female }\end{array}$ & $\begin{array}{l}15(3.5) \\
18(4.3)\end{array}$ & $\begin{array}{l}224(53.1) \\
165(39.1)\end{array}$ & 0.2 & $\begin{array}{l}16(3.8) \\
24(5.7)\end{array}$ & $\begin{array}{l}167(39.6) \\
215(50.9)\end{array}$ & 0.65 \\
\hline $\begin{array}{l}\text { Exclusive breast Feedir } \\
\text { Yes } \\
\text { No }\end{array}$ & $\begin{array}{l}\text { is) } \\
1(1.3) \\
9(12.2)\end{array}$ & $\begin{array}{l}31(41.9) \\
35(44.6)\end{array}$ & 0.02 & $8(10.7)$ & $67(89.3)$ & 0.72 \\
\hline $\begin{array}{l}\text { Nutritional status } \\
\text { Normal } \\
\text { Malnourished }\end{array}$ & $\begin{array}{l}1(0.2) \\
32(7.6)\end{array}$ & $\begin{array}{l}69(16.4) \\
320(75.8)\end{array}$ & 0.02 & $\begin{array}{l}32(7.6) \\
8(1.9)\end{array}$ & $\begin{array}{l}317(75.1) \\
65(15.4)\end{array}$ & 0.63 \\
\hline Type of diarrhea & & & & & & \\
\hline Watery & $6(1.4)$ & $128(30.4)$ & 0.27 & $13(3.1)$ & $121(28.7)$ & 0.01 \\
\hline Bloody & $0(0.0)$ & $1(0.2)$ & & $1(0.2)$ & - & \\
\hline Non bloody & $27(6.4)$ & $254(60.2)$ & & $25(5.9)$ & $256(60.7)$ & \\
\hline Bloody mucoid & $0(0.0)$ & $6(1.4)$ & & $1(0.2)$ & $5(1.2)$ & \\
\hline
\end{tabular}

common form of diarrhea observed in $281(66.6 \%)$ children, of whom 25 (5.9\%) were positive for Shigella. Statistically significant association was found between appearance of diarrhea and prevalence of Shigella $(\mathrm{p}=0.01)$. This result is in line with the finding of Jafari et al. (2008).

There was statistically significant association between breast feeding practice of the mothers $(p=0.02)$ and nutritional status of the children $(p=0.02)$ and the prevalence of Salmonella. This finding is in agreement with the findings of Rowe et al. 2004 and Vesta et al. (2010). Most mothers nowadays are advised to feed their babies with breast-milk only and not give their babies supplementary food items until the age of 6 months (Abdullahi, 2010).

As shown in Table 2, the prevalence of Salmonella species was $33(7.8 \%)$. This study is in agreement with the study conducted in Ethiopia (Getnet Beyene et al., 2011) however it is higher than the prevalence of Salmonella species in Saudi Arabia (3.3\%) (Johargy et al., 2010) but it is lower than 15.4\% prevalence in Jimma, Ethiopia (Abebe Mache et al., 1997). Nagal et al. (2006) found out that the isolation rate of Salmonella species varies from time to time and from place to place and show seasonal variation Among a total of 40 Shigella spp. isolated, 18 (45\%), 12 (30\%) and 10 (25\%) were S. flexineri, S. dysenteri and S. boydii, respectively (Table 2). This result is in line with the finding reported from Central African Republic (Manirakiza et al., 2010). This result is lower compared to that reported from Ethiopia (Moges Tiruneh, 2009) and Botswana (Urio et al., 2011), however the prevalence recorded in this study is higher than the prevalence reported from Cameroon (Yongsi, 2008) and Tanzania (Moyo et al., 2011). 
Table 2. Proportion of Shigella serotypes isolated from under five children with acute diarrhea, Bahir Dar, 2012.

\begin{tabular}{|c|c|}
\hline Bacterial Isolates & Number (\%) \\
\hline \multirow[t]{3}{*}{ Shigella spp. } & $40(9.5 \%$ \\
\hline & $18(45 \%)$ \\
\hline & $12(30 \%)$ \\
\hline S. boydii & $10(25 \%)$ \\
\hline Salmonella spp. & $33(7.8 \%)$ \\
\hline
\end{tabular}

The antimicrobial susceptibility results of Salmonella isolates are shown in Figure 1. The highest resistance was documented for ampicillin (93.9\%) followed by amoxicillin-clavulanic acid $(75.8 \%)$ which is in agreement with reports from Harrar, Ethiopia (Ayalu Reda et al., 2011). This increased resistance to anti- biotics might be due to the unwise use of antibiotics in many developing countries such as Ethiopia, which would have led to an increased antibiotic resistance and in turn reduced therapeutic efficacy in these countries (Daniel Asrat, 2008). On the other hand, in this study, the isolated Salmonella species tested showed susceptibility to ciprofloxacin and norfloxacin, (93.9\% each) followed by gentamicin $(87.9 \%)$. This result is in agreement with different studies reported from Ethiopia (Ayalu Reda et al., 2011; Daniel Asrat, 2008; Assefa et al., 1997), England (Hopkins et al., 2006), France (Wiell et al., 2006) and China (Cui et al., 2009).

The antimicrobial resistance profiles of Shigella spp. is shown in Table 3. Shigella isolates showed high resistance rates to ampicllin, amoxycillin-clavulanic acid and tetracycline. However, Shigella isolates were highly sensitive to ciprofloxacin, norfloxacin, and gentamicin. The most predominant isolates of Shigel-

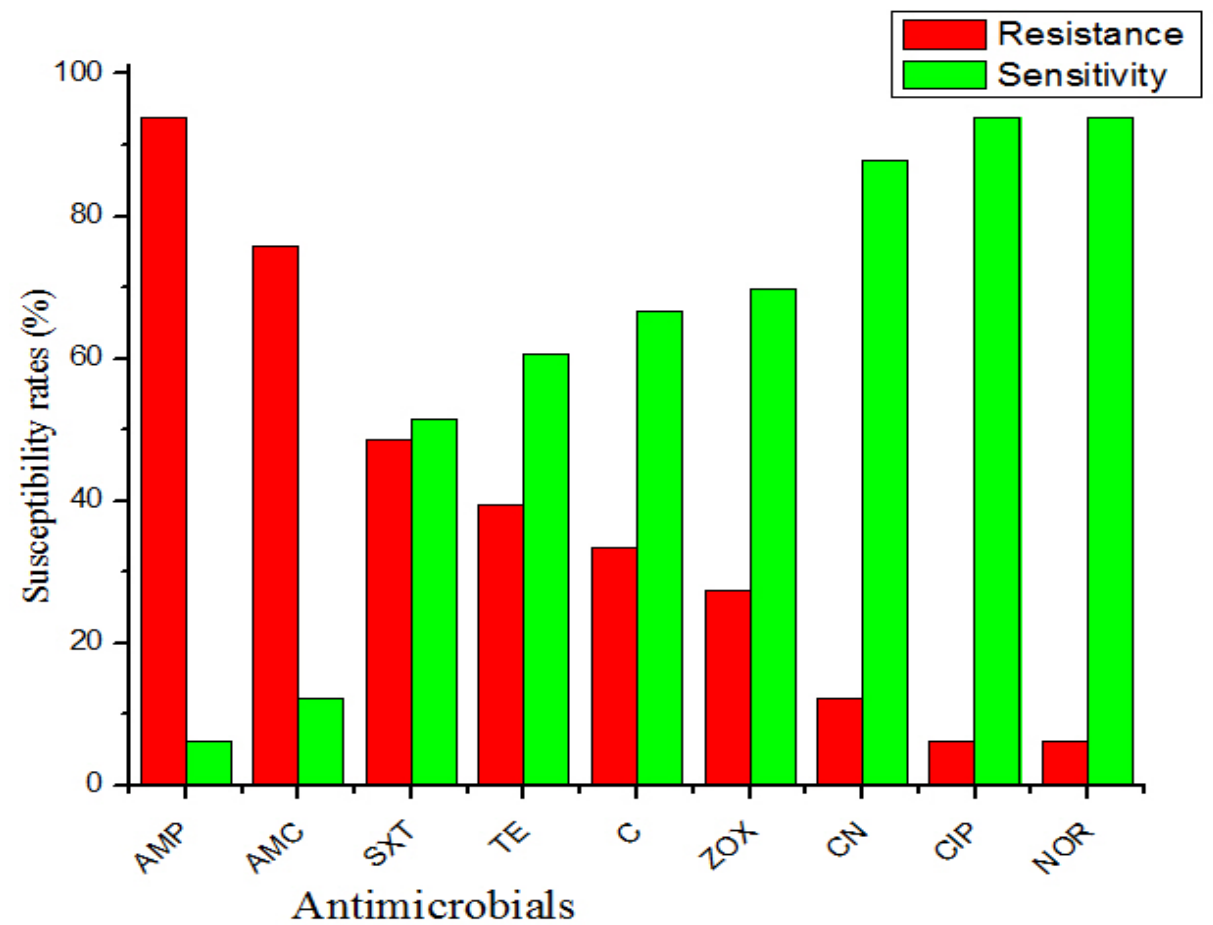

Figure 1: Antimicrobial resistance patterns of Salmonella spp. isolated form under-five children with acute diarrhea, Bahir Dar 2012.

AMP;-Ampicillin; AMC- amoxicillin/clavulanic acid;SXT- Trimethoprim-sulfamethoxazole TEtetracycline; C- chloramphenicol; ZOX- ceftizoxime; CN- gentamicin; CIP- ciprofloxacin; and NOR- norfloxacin. 
Table 3: Antimicrobial resistance profiles of Shigella isolates from under five children with acute diarrhea for commonly used antibiotics.

\begin{tabular}{llll}
\hline Antimicrobials tested & S.flexineri $(\mathrm{n}=18)$ & $\begin{array}{l}\text { S.dysenteri } \\
(\mathrm{n}=12)\end{array}$ & S.boydii $(\mathrm{n}=10)$ \\
& & 91.7 & \\
\hline Ampicillin & 88.7 & 58.3 & 50.0 \\
Amoxycillin-clavulanic acid & 77.7 & 16.7 & 10.0 \\
Chloramphenicol & 61.1 & 25.0 & 20.0 \\
Ceftizoxime & 33.3 & 0.0 & 10.0 \\
Ciprofloxacin & 11.1 & 33.3 & 20.0 \\
Trimethoprim-sulfamethoxazole & 72.2 & 8.3 & 0 \\
Gentamicin & 16.7 & 8.3 & 10.0 \\
Norfloxacin & 16.7 & 25.0 & 50.0 \\
Tetracycline & 88.9 & & \\
\hline
\end{tabular}

la spp. S. flexneri, were more resistant to amoxycillin-clavulanic acid and tetracycline than $S$. dysentery and $S$. boydii and these finding concords with results reported in Ethiopia (Belay Roma et al., 2000).

More than $90.9 \%$ of Salmonella isolates were multidrug-resistant (Table 4). The multiple antimicrobial resistances of Salmonella isolates in the present study are higher compared to the reports from other (Fadlalla et al., 2012; Okeke et al., 2005).
This might be because multiple antibiotic resistant Salmonella species increase from time to time (Nagal et al., 2006) and differ from place to place (Kariuki et al., 2006). Over $80 \%$ of the isolates were resistant to two or more antimicrobials and none of the strains were sensitive to all antimicrobials tested (Table 4). High resistance rates to ampicillin, amoxycillinclavulanic acid and tetracycline are supported by a number of studies in Ethiopia (Gizachew Yismaw

Table 4: Multiple antimicrobial resistance patterns of bacterial isolates

\begin{tabular}{lll}
\hline \multirow{2}{*}{ Antibiogram } & Bacteria & Shigella spp. \\
\cline { 2 - 3 } & & Salmonella spp. \\
\hline R0 & 6.1 & 0.0 \\
\hline R1 & 3.0 & 12.5 \\
\hline R2 & 33.3 & 17.5 \\
\hline R3 & 12.1 & 17.5 \\
\hline R4 & 18.2 & 7.5 \\
\hline R5 & 9.1 & 22.5 \\
\hline R6 & 12.1 & 15 \\
\hline R7 & 6.1 & 0.0 \\
\hline R9 & 0.0 & 2.5 \\
\hline R0 $=$ susceptible to all; R1, R2, R3, R4, R5, R6, and R7, R9 resistant to 1,2, \\
3, 4, 5, 6, 7 and 9 antimicrobials tested respectively.
\end{tabular}


et al., 2006; Moges Tiruneh, 2009) and reported in other parts of the world (Mandomando et al., 2009; Kavaliotis et al., 2002; Peridano et al., 2006).

\section{CONCLUSION}

The prevalence of Shigella and Salmonella were high in the study area. High prevalence and alarming rate of resistance to commonly prescribed antimicrobials is a serious public health problem in the study area. Exclusive breastfeeding and improved nutrition should be promoted. Continuous surveillance of antimicrobial susceptibility patterns should be done for choosing antimicrobials for empirical treatment. Ciprofloxacin, norfloxacin and gentamicin can be drugs of choice for empirical treatment of infections caused by these pathogens. This study has limitation because examination of stool alone does not ensure diagnosing typhoid fever caused by Salmonella.

\section{ACKNOWLEDGMENTS}

We would like to thank Bahir University for the financial support, through the president's fund (Grant No. BDU/RCS/Sc/03/02). We would also like to thank the parents/guardians of the children who participated in this study, whose cooperation rendered this study possible. We acknowledge the technical support of the staff of the Bahir Dar Regional Health Research laboratory centre.

\section{REFERENCES}

Abdullahi, M. (2010). Incidence and antimicrobial susceptibility pattern of Salmonella species in children attending some hospitals in Nano Metropolis, Kanostate-Nigeria. Bayero Journal of Pure and Applied Sciences 3: 202-206.

Abebe Mache, Yohannes Mengistu and Cowley, S. (1997). Salmonella serogroups identified from adult diarrheal out-patients in Addis Ababa,
Ethiopia: antibiotic resistance and plasmid resistance analysis. East African Medical Journal 74:183-186.

Aseffa, A., Gedlu, E and Asmelash, T. (1997). Antibiotic resistance of prevalent Salmonella and Shigella strains in northwest Ethiopia. East African Medical Journal 74: 708-713.

Ayalu Reda, Berhanu Seyoum, Jemal Yimam, Gizachew Andualem, Sisay Fiseha and JeanMichel, V. (2011). Antibiotic susceptibility patterns of Salmonella and Shigella isolates in Harar, Eastern Ethiopia. Journal of Infectious Diseases and Immunity 3(8):134-139.

Bauer, A. W., Kirby, W. M., Sherris, J. C.and Turck, M. (1966). Antibiotic susceptibility testing by a standardized single disk method American Journal of Clinical Pathology 45(4): 493-496.

Belay Roma, Solomon Worku, Shiferaw T/Mariam and Nina, L. (2000). Antimicrobial susceptibility patterns of Shigella isolates in Awassa. Ethiopian Journal of Health Development 14: 149-154.

Cheesbrough, M. (2006). Direct Laboratory Practice in Tropical countries. Part 2. Cambridge University Press.

Clinical Laboratory Standards Institute. (2011). Performance Standards for Antimicrobial Susceptibility Testing; Twenty Information Supplement. CLSI document M100-S21, Clinical and Laboratory Standards Institute, Wayne Pennsylvania.

Collins, C. H and Lyne, M. (2004). Microbiological Methods. $8^{\text {th }}$ edition. Oxford University Press Inc. London..

Cui, S., Li, Z.J., Sun, C., Hu, S., Jin, F., Li, Y., Guo, L and Ma, Y. ( 2009). Characterization of Salmonella enterica isolates from infants and toddlers in Wuhan, China. Journal of Antimicrobial Chemotherapy 63:87-94. 
Danile Asrat. (2008). Shigella and Salmonella serogroups and their antibiotic susceptibility patterns in Ethiopia. East Mediterranean Health Journal 14: 760-767.

Daniel, W.W. (1999). Biostatistics: A Foundation for Analysis in the Health Sciences. $7^{\text {th }}$ edition. New York: John Wiley and Sons.

Elias, C.J. (2008). Diarrhea Disease: Emergency and Humanitarian Action (EHA). World Health

Organization Week 22, Geneva.

Fadlalla, T., Mohamed, E., Ahmed, G and Mohamed, T. (2012). Antimicrobial susceptibility of Salmonella serotypes isolated from human and animals in Sudan. Journal of Public Health and Epidemiology 4:19-23.

FMoH (2011). The transformational path to achieving universal access to hygiene and sanitation. Ministry of Health Ethiopia.

Getachew Debas, Mulugeta Kibret, Fantahun Biadglegne and Bayeh Abera. (2011). Prevalence and antimicrobial susceptibility patterns of Shigella spp. at Felege Hiwot Referral Hospital, Northwest Ethiopia. Ethiopian Medical Journal 49:249-255.

Getnet Beyene, Nair S., Daniel Asrat, Yohannes Mengistu, Engers, H and Wain, J. (2011). Multidrug-resistant Salmonella Concord is a major cause of salmonellosis in children in Ethiopia. Journal of Infections in Developing Countries 5:23-33.

Gizachew Yismaw, Challa Negeri and Afework Kassau. (2006). A five year antimicrobial resistance observed in Shigella species isolated from stool sample at the Gondar University Hospital, North west Ethiopia. Ethiopian Journal of Health Development 20:194-196.

Hopkins, K.L., Davies, R.H and Threlfull, E.J. (2006). Mechanisms of quinolone resistance in Escherichia coli and Salmonella: recent developments. International Journal of Antimicrobial Agents
25:358-373.

Jafari, F., Garcia-Gil, L.J., Salmanzadeh-Ahrabi, S., Shokrzadeh, S., Aslani, M., Pourhoseingholi, M,A., Derakhshan, F and Zali, Z.R. (2008). Diagnosis and prevalence of enteropathogenic bacteria in children less than 5 years of age with acute diarrhea in Tehran children's hospital. Journal of Infection 58:21-17.

Johargy, A., Ghazi, H and Umenah, A. (2010). Frequency of viral, bacterial and parasitic enteropathogens among young children with acute diarrhea in Saudi Arabia. Journal of Pakistan Medical Association 60: 456-59.

Kariuki, S., Revathi, G., Kariuki, N., Kiiru, J., Mwituria, J., Muyodi, J., Githinji, W., Kagendo, D., Munyalo, A and Anthony, C. (2006). Invasive multidrug-resistant non-typhoidal Salmonella infections in Africa: zoonotic or anthroponotic transmission? Journal of Medical Microbiology 55: 585-591.

Kavaliotis, J., Karyda, S., Konstantoula, T., Kansouzidou, A and, Tsagaropoulou, H. (2002). Shigellosis of childhood in northern Greece: epidemiological, clinical and laboratory data of hospitalized patients during the period 1971-1996. Scandinavian Journal of Infectious Diseases 32: 207-211.

Keusch, G.T., Fontaine, O., Bhargava, A., Pinto, C.B., Bhutta Z.A., Gotuzzo, E., Rivera, J., Chow, J, Shahid-Salles, S.A and Laxminarayan, R. (2006). Diarrheal Diseases. Disease Control Priorities Project 31-49.

Laurent, P., Visser, M and Fesselet, J.F. (2005). Household drinking water systems and their impact on people with weakened immunity. MSF-Holland Public Health Department 1- 72.

Leegaard, T.M., Caugant, D.A., Froholm, L.O and Hoiby, E.A. (2000). Apparent difference in antimicrobial susceptibility as a consequence of national guidelines. Clinical Microbiology and 
Infections 6:290.

Mandomando, I., Jaintilal, D., Pons, M.J., Valles, X., Espasa, M., Mensa, L., Sigallque, B., Alonso, P.L and Ruiz, J. (2009). Antimicrobial and mechanism of resistance in Shigella and Salmonella isolated from children under five years of age with diarrhea in rural Mozambique. Antimicrobial Agents and Chemotherapy 53: 2450-2454.

Manirakiza, A., Megne-Boudjeka, P., BobossiSerengbe, G., Bercion, R and Faou, A.L.(2010). Prevalence of shigellosis diarrhea in a pediatric population: hospital based survey in Bangui, Central African Republic. Journal of Infections in Developing Countries 4: 655- 657.

Moges Tiruneh. (2009). Serodiversity and antimicrobial resistance pattern of Shigella isolated at Gondar University Teaching Hospital. Japanese Journal of Infectious Diseases 62:93-97.

Moyo, S.J., Gro, N., Matee, M.I., Kitundu, J., Myrmel, H., Mylvaganam, H., Samuel, Y., Maselle, S.Y. and Langeland, N. (2011). Age specific aetiological agents of diarrhoea in hospitalized children aged less than five years in Dares Salaam, Tanzania. MBC Pediatrics 11: 1-6.

Nagal, K., Mandial, K., Katoch, C and Chahota, R. (2006). Occurrence of Salmonella enteric subspecies enteric serovar Berta (Salmonella Berta) in bovine calves, in Himachal Pradesh, India. Veterinary Archives 76:153-157.

Okeke, I.N., Laxminarayan, R., Bhutta, Z.A., Duse, A.G., Jenkins, P., O’Brien, T.F., Pablos-Mendez. A and Klugman, K.P. (2005). Antimicrobial resistance in developing countries. Part I: recent trends and current status. Lancet Infectious Diseases 5:481-493.

Peridano, G., Souza, F and Rodriques, S. (2006). Frequency of serovars and antimicrobial resistance in Shigella spp. from Brazil. Memorias do Instituto Oswald Cruz 100:245-250.
Ranjbar, R., Dallal, M.M.S and Pourshafie, M.R. (2008). Epidemiology of shigellosis with special reference to hospital distribution of Shigella strains in Tehran. Iranian Journal of Clinical and Infectious Diseases 3: 35-38.

Rodríguez, L., Cervantes E and Rocío Ortiz, R. (2011). Malnutrition and Gastrointestinal and Respiratory Infections in Children: A Public Health Problem. International Journal of Environmental Research and Public Health 8: 1174-1205.

Rowe, Y., Rocourt, R., Shiferaw, B., Kassenborg, D., Segler, D., Marcus, R., Daily, J., Hardnett, P and Slutsker, L. (2004). Breast-feeding decreases the risk of sporadic salmonellosis among infants in food net sites. Clinical and Infectious Diseases 38::S262-S267.

United Nations Children's Fund /World Health Organization. (2009). Why children are still dying and what can be done? Geneva, UNCEFE/WHO.

Urio, E.M., Collison, E.K., Gashe, B.A., Sebunya, T.K and Mpuchane, S. (2011). Shigella and Salmonella strains isolated from children under 5 years in Gaborone, Botswana, and their antibiotic susceptibility patterns. Journal of Tropical Medicine and International Health 6: 55-59.

Vesta, R., Joselito, H., Manjari, Q., Marcelino, E., Brian, J and Cesar, M. (2010). Effect of rotavirus vaccination on death from childhood diarrhea in Mexico. New England Journal of Medicine 362:299-305.

Wiell, F.X., Bertrand, S., Guesnier, F., Baucheros, S., Grimont, A.D and Cloechaor, A. (2006). Ciprofloxacin Resistant Salmonella Kentucky in Travelers. Emerging Infectious Diseases 12:16111612.

Yongsi, H.B.N. (2008). Pathogenic microorganisms associated with childhood diarrhea in low-andmiddle income countries. International Journal of Environment Research and Public Health 5: 213229. 
